\title{
MALL-Based MOOCs for Language Teachers: Challenges and Opportunities
}

\author{
ANA IBÁÑEZ MoReno \\ Universidad Nacional de Educación a Distancia, UNED \\ JOHN TRAXLER \\ University of Wolverhampton, UK
}

Received: 5 October 2015 / Accepted: 15 December 2016

ISSN: $1697-7467$

\begin{abstract}
The present paper explores pedagogical, technical, and institutional responses to the current challenges and opportunities that MOOCs (Massive Open Online Courses) present, specifically in the area of language teaching and learning. It does so through a review of the current state of the art in the field. Besides reporting on this, the aim of the present paper is ultimately to propose the factors to be taken into account in the design of a MOOC on MALL (Mobile Assisted Language Learning) for language teachers within CPD (Continuous Professional Development), which include technical, pedagogical and linguistic standards.
\end{abstract}

Keywords: CALL (Computer Assisted Language Learning), Language Learning, CPD, Teaching tools

MOOC basados en tecnología móviles para profesores de lenguas: desafíos y oportunidades

RESUMEN: El presente artículo explora las respuestas pedagógicas, técnicas e institucionales al actual desafío que los cursos masivos en abierto (en inglés MOOCs, Massive Open Online Courses) presentan, especialmente en el área de aprendizaje y enseñanza de lenguas extranjeras. Esto se hace por medio de una revisión del estado de la cuestión en la actualidad. Además, el objetivo de este trabajo es proponer una serie de factores a tener en cuenta para el diseño de un curso $M O O C$ sobre aprendizaje de lenguas móvil (en inglés MALL, Mobile Assisted Language Learning) para profesores de lenguas extranjeras, que incluya estándares técnicos, pedagógicos y lingüísticos.

Palabras clave: aprendizaje asistido por ordenador, aprendizaje de lenguas, formación de profesores, medios de enseñanza

\section{INTRODUCTION}

This paper aims to explore pedagogical, linguistic and technical aspects of the (potential) MOOC (Massive Open Online Courses) and MALL (Mobile Assisted Language Learning) phenomena. MOOCs are dramatically increasing in number, diversity and reach, and are gaining global interest and visibility. As de Waard (2013) defines it, a MOOC is a non-defined pedagogical format to organize learning/teaching/training on a specific topic in an informal, online and collaborative way. The MOOC we propose here would take place within the context of language learning and mobiles, adapting MALL to the recognition that 
mobiles and MOOCs do not merely represent better and more engaging ways of delivering language learning but are representative of and instrumental in the transformation of both language and learning (Read and Bárcena, 2015). Emerging research (Alario-Hoyos et al., 2014, Clinnin, 2014, Czerniewicz et al., 2014) addresses perceptions of high drop-out rates and points at Continuing Professional Development (CPD) as the most effective format, capturing mature and experienced learners with high motivation for short focussed bursts. Additionally, Van Praag and Sanchez (2015) point at negative teacher believes about the mobile devices for educational purposes as one of the most important factor preventing their use for language learning purposes. They declare that the absence of detailed instruction on teacher development courses may be determining (2015: 290). Therefore, the MOOC we propose addresses language teachers.

We focus on MALL and teaching because it is a largely neglected topic in the MOOC portfolio - out of the 144 MOOCs on teacher training launched in 2014 and 2015 and the 27 launched in $2013^{1}$ there were 42 courses on e-learning or blended learning, 24 on the new technologies, only eight about language learning and teaching, and just one on mobile learning instruction design; furthermore, there was no course on MALL. In www.moocs.co, a US-based online directory for MOOCs, a list is provided of the available MOOCs for teacher development $^{2}$, we find a wide range of courses, from several providers, on blended learning or technology enhanced teaching, or on teaching pedadogies for the new learner, but, again, no courses on language teaching are found, nor any mention of MALL. Perifanou and Economides (2014) analyse the few language MOOCs available and remark on the effort of the European Commission to support open learning (for example launching the first pan-european MOOCs innitiative, www.openuped.eu) and to reshape education towards new ICT-based educational trends. However, according to them, there is still much to explore regarding the design and implementation of MOOCs with the specific focus on language learning. In line with this, we deem it necessary to propose technology configurations adapted specifically to flexible mobile delivery, to mobile learners and to technologies that promote language learning.

Looking backwards, we see mobile learning being a continuation of e-learning, of learning with computers, something that took place only in schools, colleges and universities and in corporations, institutions with the expertise and resources necessary for working with scarce, expensive, fragile and difficult devices, to enhance and extend the existing curriculum. Broadly speaking (Traxler, 2007), we can see several phases of learning with mobiles, going from, in the first place, techno-centric learning, where the defining feature was merely that the learning took place on a digital device, eventually to enriched and enhanced learning, still a legacy from learning with computers, where the extra affordances of mobile technology, for example, location-awareness, privacy, image-capture, etc., combined with existing affordances of computers, enabled the curriculum to become more flexible, personalised, situated, authentic and contextualised, as seen for example in the EU MOBIlearn project ${ }^{3}$.

\footnotetext{
${ }^{1}$ Data gathered from www.mooc-list.com, a webpage that states to provide the most comprehensive list of recently past as well as available and forthcoming MOOCs all over the world. The reader should note that this list may not be extensive and that the MOOC world is changing day by day, by the time this paper is published this information will surely be outdated.

${ }^{2}$ See http://www.moocs.co/K-12_MOOCs.html

${ }^{3}$ http://www.mobilearn.org
} 
Alongside this came extended learning, taking learning to new communities, regions and categories of learners, -still another legacy from learning with computers- for example, the EU m-learning project ${ }^{4}$. Encouraging learning -the third legacy of learning with computerswas a further category of the evolving practice of mobile learning, exploiting the mobile technologies to enthuse and encourage learners, for example, the UK 14m GBP MoLeNET programme ${ }^{5}$. User-generated learning (Cook, 2010) arrived then, marking a distinct shift away from the existing institutions, curricular and professions of education as understood and expressed in those earlier phases. This is apparent specifically in a vast amount of apps and in podcasts. Special Interest Groups (SIGs), Facebook groups, YouTube videos, blogs, are other manifestations of this trend (perhaps comparable to citizen journalism). This is very much part of the wider MOOC philosophy.

Finally, we are entering the phase of learning for mobile and connected societies, where the technologies of mobility have transformed the balance of what must be known and learnt because they are transforming the societies themselves.

The global research community that has developed now has an international professional association (International Association for Mobile Learning ${ }^{6}$ ), and continued EU projects, for example the FP7 EAGLE ${ }^{7}$ project. We see people and communities taking learning into their own hands not only as learners but as each others' teachers, and this is very much aligned to original MOOC philosophies. Therefore, a mix of MALL, MOOC and CPD programs for teachers would contribute to round up this last phase we are in.

\section{Analysis of the language mooc phenomenon: Where do We come FROM AND ARE WE GOING TO?}

Recent research on language MOOCs (Bárcena and Martín Monje, 2014) suggest an attempt to add standards to the language MOOC portfolio. Thus, Sokolik (2014) focuses on a proposal for the contents of effective languague MOOCs, Moreira Teixiero (2014), Álvarez (2014) and Read (2014) propose methodological guidelines for their design, aesthetics and architecture aspects of the language MOOCs respectively, and Castrillo (2014) delves into the role of the instructor. In this paper we draw in such recent work to add language standards, mobility and mobiles into the Common European Framework of Reference for Languages (CEFR, 2001) portfolio, by focusing on one specific target group: language teachers and trainers of teachers. This results in the proposal of where to start if we want seriously to develop and deliver an in-service sustainable CPD MALL-based MOOC.

MOOCs were created in 2007, and one year later Cormier coined the term MOOC (in Siemens, 2012) to address this type of online courses, which are mainly for higher education and, compared to the previous existent e-learning systems, are free and world-

\footnotetext{
${ }^{4}$ http://www.m-learning.org

${ }^{5}$ http://www.molenet.org.uk

${ }^{6} \mathrm{http}: / / \mathrm{www}$.iamlearn.org/

${ }^{7}$ http://www.eagle-fp7.eu/
} 
wide, open without any restriction. MOOCs can give rise to or encapsulate Communities of Practice (CoP) as described by Lave and Wenger (1991), in which communities are sharing a common understanding of purpose, process and domain. MOOCs are also growing in terms of didactic approaches to meet the new global educational challenges. The field is new, innovative, and exploratory. Following Bárcena and Martín Monje (2014), their educational model combines the removal of previous barriers such as space limitations and keeps other aspects of any educational model, such as task-based approaches and certifications.

However, some more innovation is coming, pointing at connecting instructors and learners through a common academic field. Wikipedia names it, appropriately, as another example of 'open' scholarship. This is possible only if the course is open, and works significantly better if the course is large in terms of student numbers. There is a growing research literature, often allied to the equally fast growing topic of learner analytics. Large student numbers and large amounts of on-line interactions facilitate trustworthy statistical analysis. In this sense, Godwin-Jones (2014: 12) provides a wide and exhaustive report of the state of the art of MOOCs, especially of language MOOCs, and explains the interest in this topic: "There is tremendous interest in taking advantage of the extensive data tracking by the major MOOC platforms to analyse learning patterns and identify key areas likely to need additional learner support". There is now considerable interest and investment across Europe and America in MOOCs, and they are now an established global educational phenomenon, to the point that a MOOC University has been launched (http://www.moocsuniversity.org/), which, opening in 2016, will partner with accredited higher institutions to provide "serious MOOCers" - as they call them- with pathway opportunities to get a (non-officially accredited) college degree, the necessary skill credentials to find a job, or to get promoted, or to be admitted in a college, etc.

Indeed, due to the fact that distance learning, and especially MOOCs, is relatively recent and highly interesting and massive phenomena, a lot of research is needed to identify what works and what doesn't. Godwin-Jones (2014) suggests analysing the effectiveness of peer work, experimenting with different pedagogical models, and with mixing components and establishing correlations with learning outcomes. Bárcena and Read (2015) suggest a modular structure for language MOOCs, to add up to their flexibility and adaptability to all kinds of heterogeneous learner groups and individuals, by offering more activities than necessary (by means of scaffolding) and making students complete only a certain percentage of the total. In this line of thought, it seems that we are in front of a totally new paradigm and that we need to start from the beginning, trying methodologies, techniques, contents, modules, etc., to see what works and what doesn't. We suggest here, to add up to such proposal, several methodological procedures, such as iterative delivery to test technology configurations, and building up on the CEFR (2001), to propose pedagogical and language learning standards.

MOOCs mix different formats of resources, in particular video, and various means or spaces to communicate. Whilst the differences of cultures among the participants can sometimes present challenges, it can also drive richer exchanges and greater knowledge: 
"The user mobility is turned into optimal learning opportunities that are authentic and immediately relevant to the diversity of course participants. That way a tolerant course community is created based on meaningful, professionally related interactions that enable lifelong networks" (de Waard, 2013: 80). This is especially relevant for a language MOOC (LMOOC), where language is contextualized in culture. Taking into account the results of different research findings about distance learning and MOOCs (Depover and Orivel, 2012; Mathieu Cisel and Bruillard, 2012, Czerniewicz et al., 2014) and language MOOCs (Colpaert, 2014), a point to improve seems to be the way MOOCs are usually conceived, by integrating some initial tutoring in order to encourage a peaceful and stimulating communication and a steady progression through training. As the ultimate aim in a MALL-based MOOC for CPD is to help higher education language trainers, lecturers or academics and to train language teachers, we think that it would be positive to encourage the development of peer tutoring and self-sustaining online communities with elements of e-moderating (Salmon, 2000).

\section{The Mall Phenomenon: STATE OF THE ART AND STANDARdizing PROPOSAlS}

Regarding the second area of interest for this paper, MALL, there is an on-going need for greater language competence with strategies and techniques at the forefront of mobile learning, providing timely, personalized, contextualized support for modern language learning. In this field, there have been also pilot attempts to add standards to mobile pedagogies, such as the MoTIF project ${ }^{8}$, which effectively provides useful instructional design frameworks for mobile learning, in what they call "Advanced Distribution Learning". However, there is still an area that has still not been directly addressed and articulated, which is the curriculum for language learning with mobiles. That is: language learning and teaching standards in the specific area of MALL. The Common European Framework of Reference for Languages, CEFR (2001) is an effective, guidance tool for both language learners and teachers all over the world, which leaves wide freedom for the establishing of the curriculum and methodological guidelines of language courses, as long as they comply with the current communicative approach and promote diversity and multilingualism. In the last conference on the CEFR, held in March $2014^{9}$, these guidelines were reviewed and reaffirmed. Some of the topics under discussion were the European language portfolio (Little, 2014), and the role of the framwork in Assessment (Noijons, 2014). Coste, North and Sheils (2014) highlighted that the CEFR is an instrument which offers a set of scales of reference for the specification of communicative capacities, an action oriented perspective on communication and learning, and a focus on the plurilingual and pluricultural social actor. In this line, Candelier (2014) focused in the multicultural aspects of the CEFR. North (2014) deals with the role and impact of the CEFR as an assessment, pedagogical, and standardising tool. However, up till now little has been studied about the convenience of applying it to develop serious and coherent MALL apps based on previous pedagogic and second language learning and acquisition research.

This gap has been suggested by Zerbas and Sampson (2014) and Martín Monje et al.

\footnotetext{
${ }^{8}$ See https://motifproject.org/

${ }^{9}$ See http://cefrwebconference.com/
} 
(2014). The latter authors propose the first rubric for the evaluation of mobile apps in language learning - focusing on listening skills - not only at a pedagogical and technical level but also at a linguistic level. With such a rubric they analyse a big number of apps, not only on a technical, but also on a pedagogical and on a linguistic level. For this last level they use the CEFR as a reference. Due to the fact that (presumably) most apps have overlooked the linguistic portfolio, they conclude that there is still much to be done if we want to establish some standards that allow for the creation and assessment of MALL apps. It is necessary to add linguistic and pedagogical standarDs to the MALL curriculum. Therefore, further research in this area is proposed as part of this paper, and its relationships to the phase of mobile learning entitled "user-generated learning". Here, then, we also suggest the need to look at the impact of mobiles on language itself as new linguistic practices evolve under the influence of ubiquitous and pervasive mobiles, mobility and connectedness. The results of coupling the CEFR to MALL and language MOOCs would provide long-term benefits for language teachers and learners, who would be able to benefit from better quality, pedagogically sound learner materials. Standard methodologies would be made available for language teachers, and MALL apps developers would be able to use these data to target learning goals in a more effective manner.

As regards pedagogical standards, Duman et al. (2015) state, in a study on research trends on MALL from 2000 to 2012, that most of all the JCR works they analysed did not base their research on any theoretical framework. Only Kukulslka-Hulme et al. (2015) have proposed a pedagogical framework for teachers of EFL (English as a Foreign Language) to implement mobile devices in the classroom, and to promote learning outside it too, although ubiquitous learning is not their main focus, and the CEFR is not directly addressed.

If we focus on technological standards, another important area to be explored would be to develop and test technology configurations, adapted specifically to flexible mobile delivery, mobile learners and technologies that promote language learning. Regarding languages and mobiles, in general, we believe that it is possible to make language learning more authentic, efficient, relevant, and effective by recognizing and responding to universal mobile technologies. These technologies can be viewed as (1) important delivery mechanisms, with unexploited affordances such as image-capture, speech recognition, and location-awareness, which builds on ten years of pilots, projects, and interventions; this has often been mobile learning; (2) important modifiers on the nature and extent of which language functions need to be learnt, practiced, retrieved, rehearsed, and memorized, or can increasingly be outsourced to personal mobile devices as extensions of human cognition, senses, and memory; and lastly as (3) important determinants of linguistic practices and the nature of discourses across mobile and connected societies and the ways in which the nature of learning, knowing, finding out and interacting are evolving.

Therefore, a MOOC on MALL should be also aimed at opening a line of this future research field. This would take place within the wider context of languages, learning and mobiles outlined here, adapting mobile learning, specifically MALL, to a recognition that mobiles and mobile-enabled language MOOCs do not merely represent better and more engaging ways of delivering language learning but are representative of and instrumental in the transformation of both language and learning. There is wide range of research on mobile learning from 2009 (as seen especially in the International Journal of Mobile and 
Blended Learning ${ }^{10}$ ) and on a pioneering research project on a mobile learning MOOC, mobiMOOC ${ }^{11}$, which attracted 600 students for each of two iterations. However, up till now there has not been any proposal that combines an analysis of all, that is, a proposal for a mobile enabled MOOC on MALL. In order to propose this idea, we draw on previous suggestions by Bárcena and Read (2015) and Read and Bárcena (2015), who argue that Mobile Assisted LMOOCs, which they call MALMOOCs, can increase (even more) the access of students to MOOCs and provide them with complementary tools for the courses, as long as they offer a rich and flexible way of interacting with the real world. Our aim is to propose the guidelines for the creation of the first MALL-based MOOC, but specifically addressed at language teachers, which, via several iterations, can identify those aspects that can lead to its (lack of) success.

\section{Factors to take into consideration When CREATing a MALl-based MOOC FOR TEACHER CPD}

There are several factors that have to be taken into consideration when we create a MALL app, a MOOC, a Mobile assisted LMOOC, or, ultimately, a MALL-based MOOC for teachers. We outline them in what follows:

In the first place, teacher beliefs and attitudes. Earlier research (Pajares, 1992, Campbell, 2006, Sanchez, 2013) already shows that teachers' own educational experiences as learners can determine their ideas about the usefulness of technology use in the classroom. Formed at early age, they can be very difficult to change, unless they consciously assume new roles as students. One important aspect to take into consideration when developing a MOOC on MALL that will be addressed at language teachers is precisely, then, the recipients: the teachers themselves and their beliefs about the use of mobile devices in their classroom. Van Praag and Sanchez (2015: 301), after studying three language teachers who implemented mobile devices in their classroom activities for several weeks, show these teachers saw mobile technology as time consuming and unreliable, and perceived mobile phones as distracting and disengaging. In consequence, they state, and we agree with this idea, that "teacher education courses should encourage teachers to reflect on the pedagogical benefits of mobile device usage in the classroom". Also, teachers should rely on certain (standardized) guidelines to implement mobile devices. One first attempt to promote a framework for MALL in blended or face-to-face learning is Kukulska-Hulme et al. (2015).

In the second place, we should consider the cultural aspects of our courses. Cultural factors should be taken into consideration, both when thinking about the consumers of such MOOCs and about their future MALL students. The idea of localizing MALL apps is gaining force since, even if nowadays the infrastructure and the technology configurations are globalized, the consumption of social media and apps seems to be influenced by local and cultural factors. Therefore, one aspect to take into consideration is interculturality and localization, as proposed by Byrne and Diem (2014) and Ibáñez Moreno

\footnotetext{
${ }^{10}$ See http://www.igi-global.com/journal/international-journal-mobile-blended-learning/1115

${ }^{11}$ See http://mobimooc.wikispaces.com/
} 
and Vermeulen (2015). We propose a flexible design that allows users to personalize their learning experience. As an afterthought, we should see that culture can be a feature that differentiates different physical communities; it is also a feature that differentiates different online communities.

Another very important aspect of MOOCs for our aims - and in this case MALLbased MOOCs - is to analyse the processes of design and curating. There is an increasing recognition that the role and responsibilities of lecturers need to change, however gradually. In general terms, across most subjects, including language learning, however specialist and however fast moving, there is no longer a shortage of content, nor of apps and programs, nor of communities of shared interests. As a consequence, there is a shift in how the role and responsibilities of lecturers are conceptualised, away from that of sole responsibility for creating content, stimulating discussion and defining assessment amongst a closed group of learners towards that of continually monitoring, evaluating and recommending resources, communities and materials from the wider world, from a web 1.0 format to a web 2.0 and even a web 3.0 format. This has been called curating, transforming the role of lecturer from the sole author and arbiter of content to the collector, organiser and guarantor of educational opportunities, including content and communities. These might include YouTube, podcasts, blog posts and SIGs. It can also be seen as a shift of emphasis from educational artefacts to educational experiences. Following Liyanaguawardena, Williams and Adams (2013: 5), incorporating (Open Educational Resources (OERs) is the key to local development of educational resources, and to fight MOOCs current elitism:

For higher education policymakers, administrators and educators in the developing world, while (used judiciously) OERs might offer them a basis for more cheaply developing their own fit-for-purpose (socially, culturally, and targeted to the needs and abilities of their learners) higher education systems, MOOCs may offer their learners a take-it-or-leave-it...colonial educational experience dependent on technologies only available to the already-privileged in those countries.

This is entirely in line with the original MOOC philosophy and pedagogy, which sought to leverage the wisdom of the crowd. We propose to develop this approach in order to put it on a more robust and transferable basis and to deliver practical guidelines, exemplars and standards, both pedagogic and linguistic standards (built upon the CEFR, as already mentioned) and technical standards (by testing and proposing different platforms, apps, and tools, including social book-marking, mobile reference management and recommender systems).

Fourth, as for MOOC pedagogy ${ }^{12}$, we propose an analysis of a heuristic approach that covers some of the current challenges: OER, teacher instruction, language of instruction, etc.: by way of iterative development and delivery, facilitators would use e-moderating methodologies (Salmon, 2000) to structure and scaffold interaction (Gutiérrez-Rojas et al. 2014) to improve learners' perfomance, develop peer tutoring and self-sustaining communities, in order to encourage optimal engagement and maximum learning.

\footnotetext{
${ }^{12}$ For a detailed analysis of xMOOC pedagogy, see Bali (2014).
} 


\section{Propositions to EXPlore WHEN CREATING A MOOC ON MALl FOR TEACHERS}

Up till now there has not been any proposal that combines (an analysis of) all these factors, that is, the proposal of a MOOC on MALL. This leads us to propose the one such MOOC on MALL that we anticipate will be the first, which, after several iterations, will help us identify several aspects that can lead to identifying the (lack of) success of MOOCs and this mode of ubiquitous language learning. A secondary outcome would be, out of the data obtained, to propose guidelines and standards for MALL-based MOOCs creation, curation and maintenance. A third outcome could be to deliver practical guidelines, exemplars and standards, both pedagogic and linguistic (built upon the CEFR), as well as technical standards (by testing different platforms, apps, and tools, including social book-marking, mobile reference management and recommender systems) for the elaboration, curation, maintenance, and promotion of MALL-based MOOCs for language teachers.

Another key aspect of this paper's study is to add in the increased mobilities dimension and apply it to language, epistemology, learning, culture, knowledge. Secondly, our aim is to show that by using open source models, free technologies and infrastructure, those taking this challege would be able to actually develop MOOCs for all and increase MOOCs visibility all over the world. Thirdly, a key aspect of this proposal is the combination of MOOCs, MALL, and the CEFR in order to establish solid methodological background for ubiquitous language learning. In this sense, one important modus operandi should be the still underexplored area of evaluating the linguistic and didactic validity of a large number of MALL apps, following the CEFR language levels and, if appropriate, ALTE (Association of Language Testers in Europe) guidelines, by creating rubrics and comparing them to actual mobile users' learning results. Such project would contribute to developing more homogenous and pedagogically based language learning applications, and to assessing the feasibility of standardizing MALL apps.

After this overview of what is left open for us to explore, we propose a number of lines of research that are left open for the near future: (1) What is the optimal technology mix for open free language MOOCs? (e.g. cross-platform implementation, learner interaction styles etc.?) (2) What is the optimal structuring, facilitation and moderation for open free MALL-based MOOCs for CPD? (3) What are the optimal design heuristics for curating external content and external communities for a mobile language MOOC? (4) What are the most appropriate language teaching methodologies for open free language MOOCs? Are the existing ones appropriate? Do we need new ones? (5) What are the best teaching techniques for free mobile MOOCs? Are the existing ones appropriate? Do we need new ones?

In this respect, the following propositions should be studied and analysed when creating a MALL-based MOOC for CPD: (a) Participation in MOOCs is an appropriate and meaningful form of capacity building for teachers and trainers wishing to build MALL and MOOC experiences into their subsequent professional activities. Their interchangeable roles as students and teachers within and outside MOOCs will help them develop different pedagogical skills and apply new teaching and learning techniques; (b) MOOCs represent the best opportunity to develop new design strategies that address the abundance of communities and resources for learning, to devise heuristics for curation; (c) The curricular contents in MALL apps are still not standardized. Pairing MALL courses to the CEFR will be the optimal method to provide common and effective learning standards and to test the current 
face-to-face language teaching methodologies on mobile learning. This would also apply to the MOOC proposed here; (d) MOOCs offer language teachers and teacher trainers a flexible, open, collaborative, participative, safe, space to share their expertise and development; and (e) MOOCs allow the flexibility to select and align technologies with the affordances of the learners and their lives in a mobile and connected society; (f) MOOCs represent a flexible, adaptable and responsive format in the face of rapid technological and demographic change; and (g) MOOCs allow learners and facilitators to track and exploit innovation and responses in a rapidly evolving domain.

All these propositions imply measurement and evaluation - though perhaps a more cyclic or iterative development process might build these into ongoing formative evaluation. As with much Technolgy-Enhance Learning (TEL), digital technology throws up much 'cheap' data, that is data acquired with little effort or cost. This is both an opportunity and challenge, the former clearly because system data and usage logs can be analysed with considerable confidence owing to their volume, the latter because system data and usage logs do not necessarily provide insights into motivation, only behaviour.

\section{Conclusions}

Despite the growing research on MOOCs and MALL, there is still a lot to be done regarding the new challenges of an ever-changing learning panorama. If we want to provide adequate content for MALL-based MOOCs that is useful for language trainers all over the world, we have some challenges to face. We believe that the key is first to educate educators. If we change their beliefs on the use of mobile devices in the classroom and they start to see them as allies more than as hindrances to learning, this will be a small step for us but a big step for education (Van Praag and Sanchez, 2015). Another key is scaffolding, in the sense of reusing resources, recurring to previous research on language learning, and trying to see what works and what does not work for the MOOC and MALL portfolio, and providing structure to learner activities, structure that can be progressively discarded (Mayes and De Freitas, 2004). We propose building on early involvement to deliver MOOCs iteratively, and exploring pedagogic, technical and institution responses to all the MOOC challenges: the role of instructors, OER, modularity, peer assessment. The proposed research would extend or challenge the early connectivist theorising and add considerable strategic value to much of the sector.

\section{REFERENCES}

Alario-Hoyos, C., Pérez-Sanagustín, M., Cormier, D., Delgado-Kloos, C. (2014). "Proposal for a conceptual framework for educators to describe and design MOOCs", in Journal of Universal Computer Sciences, 20, 1: 6-23.

Álvarez, I. (2014). "Ethical and aesthetic considerations in Language MOOCs", in Language MOOCs: Providing Learning, Transcending Boundaries. Warsaw/Berlin: De Gruyter Open: $127-139$. 
Bali, M. (2014). "MOOC pedagogy: Gleaning good practice from existing MOOCs", in MERLOT Journal of Online Learning and Teaching, 10, 1: 44-55, available from: http://jolt.merlot. org/vol10no1/bali_0314.pdf, last accessed October 2015.

Bárcena, E., and Martín Monje, E. (2014). "Language MOOCs: an Emerging Field", in E. Martín-Monje, E. Bárcena (Eds): Language MOOCs: Providing Learning, Transcending Boundaries. Warsaw/Berlin: De Gruyter Open,1-13.

Bárcena, E., and Read, T. (2015), "The role of modularity and mobility in LMOOCs", in Verbeia 0: 28-35, available from http://www.ucjc.edu/wp-content/uploads/2.Elena-Barcena-yTimothy\%20Read.pdf , accessed October 2015.

Byrne, J., and Diem, R. (2014). "Profiling Mobile English Learners", in The JaltCALL Journal, 10, 1: 3-19.

Campbell, S. (2006). "Perceptions of mobile phones in college classrooms: Ringing, cheating, and classroom policies", in Communication Education, 55, 3: 280-294.

Candelier, M. (2014). "Pluralistic approaches to languages and cultures", presented at The CEFR web conference, March $28^{\text {th }}$, Paris/Rome/Vienna.

Castrillo, M. D. (2014). "Language Teaching in MOOCs. The Integral role of the instructor", in Language MOOCs: Providing Learning, Transcending Boundaries. Warsaw/Berlin: De Gruyter Open: 63-87.

Council of Europe (2001). Common European Framework of Reference for Languages. Cambridge: Cambridge University Press.

Clinnin, K. (2014). "Redefining the MOOC: Examining the multilingual and community potential of massive online courses", in Journal of Global Literacies, Technologies, and Emerging Pedagogies, Special Issue on MOOCs, 2: 140-162.

Cook, J. (2010). "Mobile Learner Generated Contexts", in Medienbildung in neuen Kulturräumen, VS Verlag für Sozialwissenschaften: 113-125.

Colpaert, J. (2014). "Conclusion. Reflections on present and future. Towards an ontological approach to LMOOCs", in Language MOOCs: Providing Learning, Transcending Boundaries, Warsaw/Berlin: De Gruyter Open: 161-170.

Coste, D., North, B, and Sheils, J. (2014). "The CEFR 2001 - 2014", presented at The CEFR web conference, March $28^{\text {th }}$, Paris/Rome/Vienna.

Czerniewicz, L., Deacon, A., Small, J., and Walji, S. (2014). "Developing world MOOCs: A curriculum view of the MOOC landscape", in Journal of Global Literacies, Technologies, and Emerging Pedagogies, Special Issue on MOOCs, 2, 3:122-139.

Godwin-Jones, R. (2014). "Global reach and local practice: The promise of MOOCS", in Language Learning \& Technology, 18, 3: 5-15.

Gutiérrez-Rojas, I., Alario-Hoyos, C., Pérez-Sanagustín, M., Leony, D., and Delgado-Kloos, C. (2014). "Scaffolding self-learning in MOOCs", in Cress, U. \& Kloos, C. (Eds.), Proceedings of the European MOOC Stakeholder Summit 2014: 43-49. Lausanne, Switzerland: PAU Education, available from http://educate.gast.it.uc3m.es/wp-content/uploads/2014/02/ Scaffolding_self-learning_in_MOOCs.pdf , accessed October 2015.

Depover, C., F, and Orivel, C. (2012). Les Pays en Développement à l'Ère du e-learning, UNESCO: Institut International de Planification de l'Éducation.

de Waard, I. (2013). Analyzing the impact of Mobile Access on Learner interactions in a MOOC, unpublished Master's Thesis. Centre for distance education Athabasca University, January 2013, 135 pages.

Duman, Guler, O., Gunseli, and Gedik, N. (2015). "Research trends in mobile assisted language learning from 2000 to 2012", in ReCALL, 27, 2: 197-216.

Ibáñez Moreno, A. and Vermeulen, A. (2015). "Profiling a MALL app for English oral practice: 
a case study", in JUCS: Journal of Universal Computer Science, 21, 10. 1339-1361.

Kukulska-Hulme, A., Norris, L., and Donohue, J. (2015). Mobile Pedagogy for English Language Teachers: a Guide for Teachers. London: British Council ELT Research Papers: 14-07.

Lave, J. and Wenger, E. (1991). Situated Learning: Legitimate Peripheral Participation. Cambridge: Cambridge University Press.

Little, D. (2014). "The CEFR from the perspective of the European Language Portfolio", presented at The CEFR web conference, March $28^{\text {th }}$, Paris/Rome/Vienna.

Liyanaguawardena, T., Williams, S. and Adams, A. (2013). "The impact and reach of MOOCs: A developing countries' perspective", in eLearning Papers, 33, Reading, UK: University of Reading: 1-8. Available from http://centaur.reading.ac.uk/32452/1/In-depth_33_1.pdf , accessed October 2014.-

Pajares, M. F. (1992), "Teachers' beliefs and educational research: Cleaning up a messy construct", in Review of Educational Research, 62, 3: 307-332.

Martín-Monje, E., Arús-Hita, J., Rodríguez-Arancón, P. and Calle-Martínez, C. (2014). "REALL: Rubric for the evaluation of apps in language learning", in Proceedings of Jornadas Internacionales Tecnología Móvil e Innovación en el Aula: Nuevos Retos y Realidades Educativas, available from http://eprints.ucm.es/25096/, accessed September 2014.

Matthieu Cisel, É. B., and Bruillard (2012). Chronique des MOOC, Rubrique de la Revue STICEF, 19: 1-16. Available from http://sticef.univ-lemans.fr/num/vol2012/13r-cisel/sticef_2012_ cisel_13rp.pdf , accessed August 2014.

Mayes, T., and De Freitas, S. (2004). "Review of e-learning theories, frameworks and models", in JISC e-learning models desk study, 1: 1-8 .

Moreira Teixiero, J. M. (2014). "A proposal for the methodological design of collaborative language MOOCs", in Language MOOCs: Providing Learning, Transcending Boundaries. Warsaw/Berlin: De Gruyter Open: 33-44.

Noijons, J. (2014). "The Role of the CEFR in Assessment and Testing", presented at The CEFR web conference, March $29^{\text {th }}$, Paris/Rome/Vienna.

North, B. (2014). The CEFR in Practice. Cambridge: Cambridge University Press.

Perifanou, M. A., and Economides, A. (2014). "MOOCs for foreign language learning: an effort to explore and evaluate the first practices", in Proceedings of INTED2014 Conference, held in Valencia, Spain, 10th-12th March 2014.

Read, T. (2014). "The architectonics of language MOOCs", in Language MOOCs: Providing Learning, Transcending Boundaries. Warsaw/Berlin: De Gruyter Open: 88-102.

Read, T., and Bárcena, E. (2015). "Towards mobile assisted language MOOCs" in Mesquita, A. and Perez, P. (Eds). Furthering Higher Education Possibilities through Massive Open Online Courses, IGI Global: 226-246.

Salmon, G. (2000). E-moderating - The Key to Teaching and Learning Online. London: Kogan Page.

Sanchez, H. S. (2013). "A cognitive perspective on pre-service and in-service language teaching", in Babylonia, 1: 59-64.

Siemens, G. (2012). "What is the theory underpinning our MOOCs? Elearnspace". Retrieved Sept, 2015 from http://www.elearnspace.org/blog/2012/06/03/what-is-the-theory-that-underpinsour-moocs/

Sokolik, M. (2014). "What constitutes and effective language MOOC?" In Language MOOCs: Providing Learning, Transcending Boundaries. Warsaw/Berlin: De Gruyter Open: 16-32.

Traxler, J. (2007). "Defining, Discussing and Evaluating Mobile Learning: The moving finger writes and having writ....", in The International Review of Research in Open and Distance Learning, 8, 2: 1-11. 
Van Praag, B. and Sanchez, H. S. (2015). "Mobile technology in second language classrooms: insights into its uses, pedagogical implications and teacher beliefs. ReCALL 27, 3, 288-303.

Zervas, P., and Sampson, D.G. (2014). "Facilitating Teachers' Reuse of Mobile Assisted Language Learning Resources Using Educational Metadata", in Learning Technologies, IEEE Transactions on, 7,1: 6-16. 